\title{
APRESENTAÇÃO
}

\section{GESTOS DE RESISTÊNCIA DAS/NAS LÍNGUAS DE SINAIS}

Lívia Letícia Belmiro Buscácio (INES)

Angela Correa Ferreira Baalbaki (UERJ)

Resistência, Línguas de sinais e sujeito surdo. Muitos são os desdobramentos nestes gestos de resistência: desde ações nos movimentos sociais na luta por políticas de estado pelo surdo e pelas línguas de sinais aos saberes do lugar acadêmico sobre esse sujeito, inclusive, no lugar do pesquisador; à circulação de saberes sobre as línguas de sinais, significadas no status de língua conforme cada escopo teórico; até gestos de análise sobre as políticas linguísticas e o processo de gramatização da Língua de sinais. Neste desdobrar, saberes linguísticos encontram-se (e tensionam-se) com saberes pedagógicos na produção de diretrizes para o ensino de línguas, da Libras, da Língua portuguesa. Gestos de resistência, tomados como matéria do discursivo, são constituídos pela cisão e pela contradição no dizer de um sujeito que pensa dominar e ser origem do que diz, esquecimentos reforçados pelo lugar de produção de conhecimento, como nos ensina Pêcheux (2009). É, pois, pensar em um resistir clivado pela contradição da história e do sujeito naquilo que não damos conta e ainda assim almejamos deter, ou melhor:

a resistência se dá no interior mesmo da história (em seu motor - a luta de classes) e no interior do sujeito (em seu motor - o inconsciente). $\mathrm{O}$ sujeito - lembram? Dividido e assujeitado - se encontra aí na alienaçáo e na resistência, com suas certitudes e seus lapsos, enfim, na contradição que o constitui (FERREIRA, 2015, p. 163).

A proposta do número 55 da Fragmentum é fazer casa para as dobras nos saberes sobre o surdo e as línguas, abrigando artigos, gestos tradutórios, resenha de livro e resumos de teses de várias vertentes dos estudos linguísticos, por vezes, em elo com o pedagógico, e dos saberes pedagógicos. 
Habita também uma entrevista tecida pela escrita de uma surda, escolhida não apenas por ser surda, mas também por ocupar lugares atravessados pela resistência. Assim, ao buscarmos abrigar tantos desdobramentos teóricos e de análise sobre línguas de sinais, o surdo e a educaçáo, nosso gesto para organização da revista está baseado em um dos papéis da História das Ideias Linguísticas, conforme Colombat, Fournier e Puech (2010, p. 13): "Le rôle de l'historien des sciences du langage est donc de créer les conditions d'une réflexion informée sur l'epistemologie des sciences du langage". Em suma, a Fragmentum 55 procura, na diversidade de campos enfocados em seus artigos, abarcar diversas perspectivas sobre as Línguas de sinais, o surdo e a educação.

Cabe, então, ao pesquisador filiado à História das Ideias Linguísticas (AUROUX, 1992; ORLANDI; 1998, 2001) no encontro com a Análise de discurso (PÊCHEUX, 2009 [1988]; ORLANDI, 2007 [1996], 2009 [1999]) produzir gestos de análise sobre os campos de saber, o que, obviamente, demanda a leitura de trabalhos de cada perspectiva teórica. Segundo Chiss e Puech (1999):

\begin{abstract}
Le point de vue disciplinaire (ou disciplinarité) peut être sommairement caractérisé de quadruple manière: par rapport a l'avant, c'est-à-dire l'horizon de rétrospection où s'inscrit la $<<$ nouveauté $>>$ théorique; par raport à l'après, c'est-à-dire l'horizon de projection vers lequel tend l'objet conceptuel: par rapport à l'actuel, à la synchronie où se joue la relation aux autre discours de conaissance et aux contextes em général de l'activité théorique, la disciplinarité supposant l'interdisciplinarité, c'est-à-dire les dispositions, différences et accointances dans le jeu des disciplines; par rapport enfin à ces trois dimensions que réunissent les exigences de la transmissibilité parmi lesqueles figure (à côte de la vulgarisation dite scientifique) la didactisation à multiples étages dont le premier nous semble dèjá implique à l'intérieur même de la constitution disciplinaire (CHISS; PUECH, 1999, p. 10, nosso negrito).
\end{abstract}

Desta maneira, explicitaremos, em breves linhas, uma espécie de panorama dos estudos na área da Linguagem sobre a questáo. Distintos campos de saber e perspectivas teóricas dedicam-se a pesquisar sobre as Língua de sinais e o surdo: do que é denominado por "Estudos surdos"1 nos anos 1990/2000 para os Estudos culturais sobre sujeito surdo no XXI; dos ramos da Linguística mais estruturalista, como o Gerativismo e a Psicolinguística

${ }^{1}$ Sobre os Estudos surdos, é possível encontrar publicaçôes disponíveis para download no site da Editora Arara Azul, voltada para a área. Disponível em: <https://editora-arara-azul.com.br/ site/e-bo >. Acesso em: jun. 2020. 
e o Funcionalismo, para teorias de base linguística pelo social, como a Sociolinguística e à Linguística Aplicada; e, mais recentemente, dos estudos sobre o discurso, com a Análise de discurso, seja de orientação pecheutiana seja foucaultiana e a dita Análise de discurso americana. Soma-se ainda a Pedagogia e a Fonoaudiologia (essas, também diversas), os Estudos da tradução, as pesquisas autobiográficas, dentre outras áreas.

Os artigos, nesta edição, foram reunidos em quatro eixos. No primeiro, incluem-se os artigos que se fundamentam na base teórica, principalmente, da História das ideias linguísticas. Valéria Fernandes Nunes argumenta que leis, decretos e acordos legais, que envolvam a língua de sinais, podem colaborar com o percurso histórico e linguístico dessas línguas. Nessa perspectiva, com base nas noçôes da História das Ideias Linguísticas na relação com os Estudos Surdos, o objetivo do artigo é analisar como ocorre visibilidade social das línguas de sinais em políticas linguísticas a fim de conhecer o trajeto de sua gramatização. Mais do que um processo de gramatização propriamente dito, que passa por etapas peculiares que ainda exigem muita investigação, o artigo mostra como, ao longo do tempo, línguas de sinais de diferentes lugares do mundo desenvolvem-se e afirmam-se como línguas reconhecidas e respeitadas à luz de direitos linguísticos táo valentemente conquistados. Por sua vez, o artigo de Lívia Buscácio e Angela Baalbaki, $O$ fantasma do "monolinguismo" continua rondando: dizeres sobre a(s) lingua(s) do/no Brasil e sujeito surdo, busca analisar aspectos da política de línguas na conjuntura brasileira atual com base na História das Ideias Linguísticas, tal como desenvolvida no Brasil, e na Análise de Discurso materialista. Em particular, a partir das noçôes "discurso de" e "discurso sobre" (ORLANDI, 1990), no caso, discursos dos lugares do presidente e da primeira dama sobre a Libras, o surdo e a Língua portuguesa, apresenta gestos de análise de uma série de sequências discursivas recortadas do pronunciamento da primeiradama na posse presidencial (realizado em Libras), de Twitter do presidente da república sobre a comemoração do dia do surdo e de documento legal (o Decreto no 9.465, de 2 de janeiro de 2019). Com as análises, é possível verificar a vigência de um imaginário monolíngue persistindo, ainda que um dizer sobre bilinguismo compareça no efeito de dominante sobre as línguas.

O segundo eixo é composto por artigos que tematizam a questão da identidade surda e movimentos de resistência, inserindo questóes trazidas pelos Estudos Culturais e Estudos Surdos. Em $A$ volta do termo surdosmudos: sob uma perspectiva cultural e de identidade, de Ana Regina Campello, pretende-se (re)pensar a designação "surdo-mudo" à luz dos Estudos Culturais e dos Estudos Surdos, especialmente, desenvolvido nos campos brasileiro, 
argentino e uruguaio. A autora percorre um vasto contexto histórico - da Antiguidade à contemporaneidade -, dando destaque, sobretudo, aquele atrelado à mentalidade suscitada pelo surgimento da medicina. Nesse caminho, traz à tona vários registros da palavra "surdo-mudo", escrevendo uma espécie de história dos usos e sentidos dessa designação. Já no artigo Pesquisa acadêmica e movimento surdo: a sobreposiçāo de um fazer acadêmico e de um fazer ativista no fio do discurso, de Maria Clara Maciel de Araújo Ribeiro e Glaucia Muniz Proença Lara, pode-se verificar como a questão da identidade discute a noção de éthos em análise de sequências discursivas recortadas de uma tese de doutorado em Educação produzida e defendida por uma surda militante na UFSC, em 2010. No artigo, unem-se os estudos da Análise de Discurso de base enunciativa a pesquisas relacionadas ao movimento social surdo. As análises buscam depreender as imagens de si (militante e pesquisadora surda) produzidas na parte identificada como introdução da referida tese. A autora destaca que a sobreposição entre sujeito e objeto da pesquisa resulta em arranjos discursivos que promovem tensóes constitutivas entre um fazer acadêmico e um fazer militante.

$\mathrm{O}$ terceiro eixo compreende artigos que tematizam questóes relacionadas ao processo de tradução e interpretação entre a Libras e a Língua Portuguesa. No artigo Luz, palco e a caracterização de tradutores intérpretes de Libras- Português em peça teatral, de Neiva Aquino Albres e Wanderley Martins dos Santos, pautados em uma perspectiva dialógica (BAKHTIN; VOLOCHINOV, 1997) aliada aos estudos da tradução de Línguas de sinais, analisaram documentos da peça "X-QUEM? - Origens" sobre o papel do Tradutor-intérprete de Libras e Língua Portuguesa (TILSP) em um espetáculo teatral. Os autores verificaram que a atuação do TILSP no teatro pode ir além da mera tradução simultânea, por estar marcada pelo "corpo do tradutor em cena", rompendo com um imaginário de tradutor neutro ou isento do processo, ainda ecoa no lugar do tradutor intérprete. Neste sentido, o lugar do TILSP passa a significar como um corpo que integra o espetáculo teatral, deixando de ser um mero apêndice para acessibilidade em Libras no espetáculo, para ocupar um lugar na performance teatral. E, nesse lugar, por sua vez, a Língua de sinais passa a outra ordem, no encontro com a Língua Portuguesa, marcado pela tensáo entre a visualidade e a oralidade na cena do espetáculo. No artigo, As formas de tratamento e a interpretaçáo da libras para o português brasileiro: polidez e poder, de Maria Cristina Pires Pereira, aponta-se, sobretudo, para regras de polidez em Libras comparadas às regras de polidez correspondentes em português, com enfoque no trabalho do tradutor-intérprete de Libras/Língua portuguesa. Indo além das diferenças 
entre os dois conjuntos de regras, o artigo aventa a possibilidade de que algumas dessas estratégias de polidez estão ligadas às próprias características linguísticas de uma língua gestual-visual, enquanto outras estratégias são oriundas de aspectos sociolinguísticos específicos dos sinalizantes. Assim, o artigo oferece um ponto de vista interessante e fecundo para pesquisas na área.

O quarto eixo contempla a discussão referente aos processos pedagógicos com a discussão sobre o conceito de letramento em relação ao sujeito surdo no ensino superior e a produçáo de materiais didáticos de ensino de Língua portuguesa para surdos na educação básica. Tais questôes são muito caras à área, se considerados os quase 10 milhôes de brasileiros que são surdos, bem como o número ainda restrito de alcance de açóes públicas para atender as expectativas dos mesmos e, principalmente, de melhoria na sua aprendizagem da Libras e Língua Portuguesa, compreendida nestes estudos como segunda língua (LP2). Em Letramentos e identidades: vivências, práticas e contextos de estudantes surdos, Danielle Cristina Mendes Pereira Ramos debruça-se sobre os processos de letramentos de surdos com base no campo dos Novos Estudos de Letramento (NEL), Multiletramentos e de Multimodalidade (JEWITT, 2008; KRESS, 2003). A autora trabalha com enfoque os conceitos de letramento autônomo e letramento ideológico (STREET, 2014) e de comunidade de práticas (ECKERT; MC CONNELGINET, 1992) para analisar processos de letramento de surdos em cursos de graduação no Ensino Superior. Já Fernanda Beatriz Caricari de Morais e Osilene Maria de Sá e Cruz, no artigo Plano de atividades e unidade didática: ferramentas para o ensino de leitura e escrita de lingua portuguesa para alunos surdos, propóem construir uma proposta de planejamento e de produçáo de unidade didática para ensino dessa língua para surdos. Além de uma proposta de metodologia para a produção de material didático em uma perspectiva bilíngue que considere a Libras como a primeira língua do aluno surdo, o artigo abre para a discussão sobre a produção de novos instrumentos de ensino adequados a esse alunado, considerando, a partir de uma concepção sociointeracionista, o ensino como uma prática baseada em tarefas. Sua principal proposta é apresentar um modelo de Plano de Atividade (PA) e relacioná-lo a uma Unidade Didática (UD). Com uma proposta de prática pedagógica, o artigo contribui ao buscar promover um deslocamento na produção de materiais didáticos para surdos, a qual ainda, como apontado por pesquisadores da área, reproduz atividades restritas a listas de palavras e/ou cópias mecânicas.

Seguindo o percurso deste número da Fragmentum, adentramos 
na entrevista realizada por Phellipe Marcel da Silva Esteves e Elissandra Lourenço Perse com Carilissa Dall'Alba. Carilissa é professora da UFSM, surda congênita e com grande representatividade na comunidade surda, por sua atuação em diversas frentes de luta: "Legenda para quem não ouve, mas se emociona"; "Escola bilíngue para surdos"; e dando visibilidade no movimento LGBT's para surdX, dentre outros. Um ponto importante: a entrevista " $O$ que nos salva é minoria (...) $O$ assistencialismo está voltando com toda força", traz um sabor da língua escrita por uma surda, isto é, uma escrita marcada por transitar entre a Libras e a Língua portuguesa. Carilissa Dall'Alba optou por respondê-la em língua portuguesa escrita e os entrevistadores, Phellipe Marcel e Elissandra Perse, juntamente com as organizadoras e a equipe editorial, promoveram um gesto de não 'normatizar', de não 'consertar a escrita de um surdo' na busca por uma língua imaginária: foi tomada a posição de não apagar as marcas da Libras e da visualidade da experiência surda na escrita em Língua portuguesa de Carilissa, uma escrita entre-línguas e linguagens, identificada a um 'ser surdo' enquanto lugar na memória do dizer.

Além dos artigos e da entrevista, outra contribuição desta edição é a tradução do artigo $A$ didática da língua de sinais francesa: nascimento ou reconhecimento de uma disciplina de pleno direito?, produzida por Décio Rocha. O artigo das autoras francesas, Véronique Geffroy e Élise Leroy, oferece algumas ideias sobre a qual ramo de estudo a língua de sinais francesa e sua didática devem pertencer adequadamente. Mostra-se como, ainda que persista um dizer que confira um status menor a língua de sinais enquanto objeto de pesquisa, a língua de sinais francesa (LSF) vêm se tornando um objeto de estudo nas universidades. $\mathrm{O}$ objetivo do texto não é enfatizar as particularidades da cultura surda, mas, no entanto, reforçar que a língua e a cultura são inseparáveis ao discutir o ensino de idiomas.

$\mathrm{Na}$ seção destinada à resenha, Ricardo Janoário, em Leitura e escrita na educação de surdos: das políticas às práticas pedagógicas, que se dedica à apresentação da obra intitulada Leitura e escrita na educaçáo de surdos: das políticas às práticas pedagógicas (2015) organizada por Tiago Ribeiro e Aline Gomes Silva. No seu texto, Ricardo Janoário identifica as propriedades da obra e sua relevância ao pensar a diferença e a educaçáo para surdos. Com teor reflexivo, a resenha faz-nos compreender a importância do livro no cenário da educação para surdos.

Por fim, esta ediçáo conta com dois resumos que colocam em cena duas teses. Fernanda d'Olivo, em $O$ ensino de português para surdos pelo olhar 
do professor de português como segunda lingua, resume a tese de Roberval Teixeira e Silva (2004), que busca delinear um programa de ensino bilíngue para surdos, com base no campo da sociolinguística interacional, sobretudo com o conceito de Letramento ideológico. Marcela Dezotti Cândido traz o resumo da tese de Cláudio Henrique Mourão, surdo e professor da UFRGS, intitulada Literatura surda: experiência das mãos literárias (2016). Estabelecendo uma relaçáo entre os Estudos culturais e os Estudos surdos, o autor analisa e dá visibilidade ao que denomina como aspecto "visualiterário" da Libras como manifestaçáo de um elo entre a língua de sinais e o sujeito surdo, atravessando a formação identitária e cultural.

Terminamos esta apresentação esperando que os diferentes trabalhos aqui expostos possam auxiliar o leitor a desenvolver um panorama amplo de visóes sobre línguas de sinais, proposta bilíngue para surdos e formas de letramento, reflexóes sobre tradução e questôes identitárias e culturais de surdos. Em outros termos, possibilite ao leitor uma visada de parte das pesquisas sobre Língua, educação e sujeito surdo que vêm dando corpo ao atual cenário acadêmico da área. Um panorama que, ao mesmo tempo, apresenta limites, deixa perguntas à deriva, mas abre fronteiras para inquietaçóes que, certamente, levarão a outros debates e questionamentos.

\section{Referências}

CHISS, Jean-Louis; PUECH, Christian. Le langage et ses disciplines XIXe - Xxe siècles. Paris, Bruxeles: Editions Duculot, 1999.

COLOMBAT, Bernard; FOURNIER, Jean-Marie; PUECH, Christian. Histoire des idées sur le langage et les langues. Paris: Klincksieck, 2010.

FERREIRA, M. C. L. Resistir, resistir, resistir... Primado prático discursivo! In: SOARES, Alexandre S. Ferrari et al. Discurso, resistência e... Cascavel: Edunioeste, 2015.

PÊCHEUX, Michel. Semântica e discurso: uma crítica à afirmação do óbvio. Campinas: Unicamp, 2009 [1988].

. Discurso, estrutura ou acontecimento. Campinas: Pontes, 2006 [1983].

ORLANDI, Eni. Língua e conhecimento linguístico: para uma história das ideias no Brasil. São Paulo: Cortez, 2002. 
. Política linguística no Brasil. Campinas: Pontes, 2007.

. Interpretaçáo: autoria, leitura e efeitos do trabalho simbólico. Campinas: Pontes, 2007 [1996].

Análise de discurso: princípios e procedimentos. 8. ed. Campinas: Pontes, 2009 [1999].

REVUZ, C. A língua estrangeira entre o desejo de um outro lugar e o risco do exílio. (Trad. por Silvana Serrani). In: SIGNORINI, I. (Org.). Língua(gem) e identidade. Campinas: Mercado de Letras/FAPESP/FAEP, 1998. p. 213-230. 